\title{
SITUACIÓN DE LA PROPIEDAd INTELECTUAL Y SU RELACIÓN CON LA ACTIVIDAd AgROPECUARIA EN CENTRO AMERICA
}

\author{
José RENÉ ORUE CRUZ \\ Profesor Adjunto de Derecho Mercantil \\ Universidad Centroamericana
}

\section{PROPIEDAD INTELECTUAL}

L

a propiedad intelectual tiene por objeto la protección de los bienes inmateriales, que podemos definir como prestaciones producto de la creación o el esfuerzo humano, que se materializan en determinados bienes que encierran extraordinario valor informativo, de gran relevancia en el mercado moderno.

Característica esencial de los bienes inmateriales, como su propio nombre indica, radica en que consisten en ideas o prestaciones inaprensibles sensorialmente en cuanto tales pero materializada en elementos materiales sobre las que se proyecta la protección jurídica especial otorgada por el ordenamiento jurídico.

El núcleo esencial de los distintos derechos de propiedad intelectual consiste en un derecho de exclusiva, que confiere a su titular no sólo la facultad de explotar el bien inmaterial, sino también de impedir que pueda ser utilizado por terceros. En función del contenido informativo de cada uno de los derechos de propiedad intelectual, podemos distinguir tres grandes grupos de bienes inmateriales: Las creaciones industriales, creaciones intelectuales, y derechos de propiedad intelectual sui generis.

Las creaciones industriales incorporan información técnico- industrial, y pueden ser objeto de protección mediante derechos de propiedad industrial como las patentes, los modelos de utilidad, marcas, semiconductores; las creaciones intelectuales son bienes inmateriales que vinculan información estético- industrial, y que gozan de protección al amparo del derecho de autor y los derechos conexos; los derechos de propiedad intelectual sui generis, son aquellos que están relacionados a las nuevas aplicaciones biotecnológicas, obtenciones vegetales, etc.

\subsection{Principio de territorialidad}

Producto de los procesos de integración de los mercados la protección jurídica de la propiedad intelectual se encuentra gobernada por el principio de territorialidad, eso significa que cada legislador nacional determina de forma autónoma e 
independiente el objeto, requisitos materiales y formales, efectos y duración de las diversas modalidades de propiedad intelectual. De ahí se sigue, entre otras consecuencias, la limitación de su eficacia al territorio del Estado que reconoce su tutela y, en consecuencia, la necesidad de satisfacer las exigencias, y en particular los requisitos de obtención y mantenimiento puestos por la legislación de cada Estado para asegurarse la protección en su respectivo territorio.

Las dificultades que representa, lo antes señalado, al comercio internacional son muy claras y afectan a los Estados. Para enfrentar esos y otros obstáculos, en el siglo XIX se suscribió el primer tratado internacional conocido como el Convenio de la Unión de París para la Protección de la Propiedad Industrial. Desde entonces y hasta la fecha, la respuesta de los Estados a los obstáculos y dificultades implícitas en el fraccionamiento de la protección jurídica de la propiedad intelectual se ha dirigido a tres direcciones fundamentales. El establecimiento del principio de trato nacional, la imposición de una protección mínima en favor de los nacionales de otros Estados y la simplificación de los procesos de obtención y conservación de los derechos de propiedad intelectual.

\subsection{Globalización}

La situación anterior determinada por el principio de territorialidad y la solución planteada por medio de un entramado de Tratados Internacionales que garantizan y simplifican el acceso a los diversos sistemas nacionales podría considerarse garantizado. Pero sucede, que la nueva realidad genera un cambio de óptica para afrontar los problemas que genera la protección jurídica de la propiedad intelectual en el ámbito internacional. Tradicionalmente se trataba de superar los obstáculos que representaba el principio de territorialidad desde una perspectiva técnica, pero como superar a los obstáculos que surgen desde una perspectiva económica y política. Una vez superadas las trabas derivadas del principio de territorialidad, es decir trabas al libre comercio de productos y servicios, el desarrolló tecnológico, la capacidad innovadora y la creatividad empresarial en los ámbitos industrial y comercial son los factores clave de la competitividad de las empresas.

Reflejo de esta aproximación en el plano internacional es la integración de la protección jurídica de la propiedad intelectual en el sistema de comercio multilateral por medio de la Organización Mundial de Comercio y su incorporación institucional y normativo al lado del comercio de bienes y de servicios. 


\subsection{Regionalización}

En ese contexto del comercio multilateral, no puede obviarse el papel protagónico de los organismos internacionales y regionales, así menciono el papel de la Organización Mundial de la Propiedad Intelectual, el Consejo de los Acuerdos sobre los Aspectos de los Derechos de Propiedad Intelectual, el Consejo de la Unión Internacional para la Protección de Ias Obtenciones Vegetales, el Sistema de Integración Centroamericano, etc.

\subsection{Armonización}

El avance de la globalización e integración regional de las economías ha comenzado a impulsar un proceso de armonización de la legislación nacional en materia de propiedad intelectual.

El proceso de armonización no se limita al ámbito del Acuerdo sobre los Aspectos de los Derechos de Propiedad Intelectual Relacionados con el Comercio ADPIC, puedo mencionar, además, el Tratado de Patentes, el Sistema de Solución de Controversias, y otros.

Es de esperar un proceso de armonización de las legislaciones nacionales a impulso de los organismos internacionales y regionales, también se debe esperar un proceso paulatino de unificación de la protección jurídica de la propiedad intelectual. Incluso, la evolución, dependiente del éxito de los procesos de integración de los mercados nacionales apunta a la aparición de unos derechos de propiedad intelectual supranacionales.

Cabe mencionar que actualmente las reglas de convivencia entre derechos de propiedad intelectual comunitarios y nacionales adoptan dos modelos diferentes.

Las indicaciones geográficas y denominaciones de origen, las obtenciones vegetales son incompatibles con los derechos nacionales. En cambio, las marcas son acumulables con los de carácter nacional.

\subsection{Nueva realidad tecnológica}

Las modalidades de propiedad intelectual existentes pueden ser estructuralmente adecuadas para satisfacer las exigencias de protección jurídica resultantes del cambio tecnológico. Pero, se afirma que la realidad tecnológica no guarda correspondencia con la realidad considerada por el legislador para el diseño de los diferentes aspectos de cada modalidad de propiedad intelectual. 
Ejemplo de lo anterior, encontramos con la protección de invenciones relacionadas a los microorganismos a cuyas particulares características no respondían las normas en su momento existentes a cerca de la solicitud de patentes y para lo cual se desarrolló un específico sistema de depósito (Tratado de Budapest).

Los retos que desde esta perspectiva se plantean son de extraordinaria importancia, tal es el caso de la protección de las invenciones biotecnológicas.

El desarrolló de la biotecnología es clave para el avance en sectores de gran importancia económica y social, como son la producción agropecuaria, medicina, bioremediación, etc.

El éxito exige una suma de decisiones empresariales que esperan la superación de aspectos técnicos que permitan al sistema de patentes ofrecer una mejor protección a las invenciones que se produzcan en los campos antes mencionados.

La aplicación de biotecnología implica la modificación de los códigos genéticos de microorganismos, plantas, animales y el ser humano, por lo que cualquier medida que pueda fomentar su desarrolló debe asegurar la salud y seguridad humana, animal y el medio ambiente, además de ciertas exigencias de orden ético y moral.

Para un adecuado proceso de transformación agropecuaria en Centroamérica se debe disponer del andamiaje jurídico moderno en materia de propiedad intelectual.

Para que la actividad agropecuaria se desarrolle con la seguridad jurídica de que los frutos de la investigación y desarrolló serán tutelados, es fundamental disponer de un marco regulatorio moderno y además contar con un estado de derecho, tengamos presente que los derechos de propiedad industrial y los derechos sui generis lo que persiguen es proteger al inventor, al obtentor, al titular de esos derechos y sus causahabientes.

Existen diferentes criterios en cuanto a que si la propiedad intelectual favorece al productor agropecuario, o si favorece al que dispone capacidad para investigar.

Cabría preguntarse entonces: Si la propiedad intelectual favorece o no a los países centroamericanos.

Afirma Ricardo Garón Figuls, ex Ministro de Agricultura de Costa Rica, que el enfoque no debe ser si la propiedad intelectual favorecerá a nuestros países. “ $\mathrm{Al}$ contrario, si no entramos en la protección de los descubrimientos que hagamos, nunca vamos a generar nada, ni vamos a tener gente interesada en investigar. Además ya no se trata de si queremos o no la propiedad intelectual, es un com- 
promiso adquirido por nuestros países, con la firma de los diferentes convenios internacionales.

La propiedad intelectual no debe verse con temor, sino más bien como una herramienta o recurso a favor de nosotros. Cómo logramos esto?. Cómo hacer para que haya más investigación en nuestros países?. Cómo mejoramos más especies ?. Cómo sacamos más provecho de la biodiversidad ?. Cómo las protege a favor de nuestros agricultores?. Esto es otro enorme reto que tenemos.

Desde esta perspectiva la propiedad intelectual debe visualizarse no como una limitante para acceder a tecnologías, sino más bien como un elemento estratégico para tener acceso a ellas, para atraer inversión extranjera, para promover el desarrolló de la investigación en el sector público y privado y para poder introducirnos en los mercados internacionales en igualdad de condiciones. No cabe duda de que debemos preocuparnos por cumplir con los compromisos adquiridos en convenios internacionales, pero más debemos preocuparnos en crear estructuras legales apropiadas para regular el acceso y uso de los recursos y al mismo tiempo estimular la inversión en investigación.

En definitiva cualquier decisión que se tome debe contemplar las premisas de la Alianza Centroamericana para el desarrolló Sostenible que han definido nuestros presidentes y eso implica que el rumbo a seguir deberá enmarcarse dentro de los cuatro pilares del desarrolló sostenible en lo económico, social, ambiental y ético".

\section{Biotecnología}

Es importante conocer las nuevas definiciones, términos y aplicaciones, en especial aquellas relacionadas de forma directa al sector agropecuario. Con estos términos estaremos en constante contacto y evolución en los próximos años, siendo algunos de estos: La biotecnología moderna, animales y vegetales modificados genéticamente, patente de biotecnología, depósito de microorganismos, etc.

Comencemos con el término biotecnología, el cual un su acepción más amplia, designa el uso de microorganismos vivos con el fin de obtener productos útiles para la humanidad. A pesar de lo novedoso del término, se considera que la biotecnología no es una invención reciente; por el contrario, ha sido utilizada por el hombre a lo largo de su historia en la elaboración de bebidas fermentadas como la cerveza y el vino, igualmente en la obtención de derivados de la leche como el queso y el yogurt. En estos casos, bacterias y levaduras son los entes encargados de llevar a cabo el proceso de transformación de diversos compuestos. 
Hasta hace poco tiempo, no se conocían con exactitud ni las reacciones bioquímicas, ni los determinantes genéticos involucrados en los procesos metabólicos responsables de estas transformaciones. Se producía vino, pero no se sabía en qué forma. Nos encontramos, entonces, con productores empíricos cuyo conocimiento era transmitido por generaciones. $\mathrm{Al}$ igual que los productores agropecuarios, los que durante siglos han desarrollado razas de animales y variedades vegetales ( perro chichuahua en México, o trigo en Egipto) con características seleccionadas a través de la manipulación del proceso de fertilización, pero desconociendo las bases de la genética.

Correspondió al monge Gregorio Mendel establecer las leyes que gobiernan el intercambio y la transmisión de los factores hereditarios, en respuesta al interés despertado en el Siglo XIX en Europa por la reproducción de híbridos frutales. Fue el sabio Mendel quién por primera vez postuló (1867) la existencia de genes y su participación en la transmisión de los caracteres. Pero, transcurrió más de un siglo para que se conociera la manera exacta de manipular este patrimonio hereditario (el genoma) con el fin de obtener organismos con características definidas de antemano, por medio de la ingeniería genética.

La biotecnología y en particular su instrumento más versátil, la ingeniería genética, han desplazado otras áreas del conocimiento humano. Conviene retomar la metáfora de Paul de Kruif , mencionada en la obra Biotecnología y Propiedad Intelectual; Andrade Raíza y otros autores; LIVROSCA; Caracas, 1999:

"Los cazadores de genes de la actualidad han desplazado a los cazadores de enzimas de los años 70, quienes a su vez habían desplazado a los cazadores de vitaminas de los 50, y estos a los cazadores de microbios de principios del siglo XX'.

Se afirma por destacados investigadores, que la era de los cazadores de genes ha sido consecuencia directa del desarrolló de la ingeniería genética a raíz del descubrimiento de las leyes y los procesos enzimáticos que gobiernan la genética a nivel molecular. Se sostiene que a mediados de los 50 James Watson y Francis Crick lograron dilucidar la estructura y función del material genético: el ácido desoxirribonucléico o ADN. Posteriormente se fue completando el rompecabezas que permitió establecer la conexión entre el mensaje genético, cifrado en forma de una secuencia de nucleótidos (las bases estructurales del ADN) y la estructura de las proteínas, responsable finales de la actividad celular. En los 60 se avanzó en la enzimología de los ácidos nucléicos, identificándose las enzimas responsables de los procesos de duplicación del AND y la transcripción del 
ADN en ARN; además se aclaró la estructura y la función de los genes a nivel molecular.

El descubrimiento de una enzimas muy particulares, las endonucleasas de restricción, capaces de cortar el ADN en sitios específicos, abrió las puertas de la manipulación genética, por medio del corte y empalme de diferentes genes y su incorporación en el interior de células vivas (clonación molecular) Siendo la tecnología del ADN recombinante, ingeniería genética, el punto de partida de una nueva etapa en el campo de la biotecnología pues permitió modificar y clonar genes, alterando la función de las células y obligándolas a producir cualquier producto.

\subsection{Veamos algunas acepciones a cerca del significado de la palabra bio- tecnología:}

Iver Cooper expresa: " Biotecnología es una nueva palabra para una vieja idea, la idea de una nueva tecnología basada en el uso de cosas vivas. La elaboración de la genética mendeliana y el reconocimiento del papel de la mutación fueron los primeros pasos de una lejana biotecnología empírica".

La Organización para la Cooperación y Desarrollo Económico OCDE afirma que biotecnología es : " La aplicación de principios técnicos y de ingeniería para el procesamiento de materiales, a través de la utilización de agentes vivo y con la finalidad de producir bienes y servicios".

El Convenio de Diversidad Biológica establece que : "Biotecnología se entiende toda aplicación tecnológica que utilice sistemas biológicos y organismos vivo o sus derivados para la creación o modificación de productos o procesos para usos específicos".

\subsection{El Protocolo de Cartagena sobre Bioseguridad de la Biotecnología ex- presa:” Por biotecnología moderna se entiende la aplicación de:}

a- Técnicas in vitro de ácido nucléico, incluidos ácido desoxirribonucleico ADN recombinante y la inyección directa de ácido en células u orgánulos, $\mathrm{O}$

b- La fusión de células más allá de la familia taxonómica, que superan las barreras fisiológicas naturales de la reproducción o de la recombinación y que no son técnicas utilizadas en la reproducción y selección tradicional. Pero recordemos, que para la obtención de variedades vegetales se dispone de técnicas tradicionales o convencionales (biotecnología tradicional) siendo la más usual en Centroamérica. Las técnicas tradicionales han sido utilizadas desde la 
antiguedad, ya que el hombre siempre ha tenido interés y afán por obtener variedades vegetales que le sean provechosas. Básicamente consiste en el cruce y la selección de la descendencia; adicionalmente se utilizan agentes mutagénicos para obtener poliploidías.

En cambio, las técnicas modernas (biotecnología moderna) comprende el cultivo de tejidos in vitro, fusión de cloroplastos y la ingeniería genética.

Sostienen expertos, que en la agricultura la biotecnología tiene múltiples aplicaciones, entre ellas la reproducción acelerada de plantas, la obtenciones de semilla libre de enfermedades, la conservación de germoplasma y el desarrollo de variedades a través de la ingeniería genética. Esto ultimo es especialmente importante si se considera la carencia que tienen nuestros agricultores de cultivares y los centros de investigación nacional y que permitan una producción más eficiente y sostenible; además permite, identificar o no en corto tiempo, las características deseadas en un cultivar.

\section{Instrumentos internacionales}

A continuación efectuaré análisis de los principales Convenios Internacionales en materia de propiedad intelectual y que guardan relación estrecha con la actividad agropecuaria.

\subsection{Convenio de la Unión de París para la Protección de la Propiedad Industrial}

Se afirma que es el documento más importante del régimen internacional de la propiedad industrial, adoptado el 20 de marzo de 1883, constituye una solución, frente a la diversidad de legislaciones de los Estados, para proteger internacionalmente a los titulares de derechos garantizándoles ciertos privilegios en cada país miembro de la Unión; además trajo como ventaja la aplicación de una regla general entre los Estados de la Unión, tornado una mayor seguridad para la armonización, equilibrio y concentración de interés; establece niveles mínimos de protección y de seguridad jurídica para los titulares.

La Convención de París nace debido a la insuficiencia de protección a las patentes de invención cuyas disposiciones eran insignificantes, pues correspondía a simples promesas carentes de algún efecto jurídico inmediato.

Las normas que integran la Convención se agrupan de la siguiente forma:

- Contiene disposiciones de derecho internacional público que regulan los derechos y obligaciones de los Estados Miembros y establecen los órganos 
de la Unión creados por el Convenio, así como disposiciones de carácter administrativo.

- Disposiciones que exigen o permiten a los Estados Miembros legislar dentro del campo de la propiedad industrial.

- Legislación sustantiva en el campo de la propiedad industrial por lo que respecta a los derechos y obligaciones de las partes privadas, pero únicamente en la medida en que lo exija la ley interna de los Estados Miembros que se haya de aplicar a esas partes.

- Contiene disposiciones de derecho relativas a los derechos y obligaciones de las partes privadas, normas que sin embargo, no se refieren únicamente a la aplicación de las leyes internas, puesto que su contenido puede regir directamente la situación en cuestión.

A pesar de lo antes enunciado, conviene aclarar, que el Convenio en su alcance es limitado, al dejar a sus Estados Miembros en libertad de legislar sobre cuestiones de propiedad industrial de acuerdo a sus intereses.

El Convenio de París, corresponde a un tratado ley, eso significa que en cada uno de los Estados Miembros opera como una ley, y por consiguiente de aplicación obligatoria

$\mathrm{Al}$ aceptar un país el carácter autoejecutivo del Convenio, las autoridades administrativas y judiciales deben aplicar directamente las disposiciones del Convenio de París a las partes privadas sin intervención de ley interna.

Algunas de las disposiciones a destacar de la Convención, son:

- Unión de París

Los Estados Miembros del Convenio de París constituyen una Unión para la protección de la propiedad industrial. Esta Unión, conocida como la Unión de París, es una persona jurídica de derecho público internacional. Dispone de sus órganos rectores a saber: Asamblea de la Unión, el Comité Ejecutivo y la Oficinal Internacional de la Organización Mundial de la Propiedad Intelectual OMPI.

- Objeto

La protección de la propiedad industrial tiene por objeto las patentes de invención, los modelos de utilidad, los dibujos o modelos industriales, las marcas, el nombre comercial, las indicaciones de procedencia o denominación de origen, así como la represión de la competencia desleal.

La propiedad industrial se entiende en sentido amplio y no sólo se aplica a la industria y al comercio, sino también al dominio de las industrias agrícolas y extractivas y a todos los productos fabricados o naturales, por ejemplo: vinos, 
granos, hojas de tabaco, frutos, animales, minerales, aguas minerales, cervezas, flores, harinas.

- Trato Nacional

Incorpora este importante principio, es decir, los extranjeros miembros de Estados de la Unión gozarán de la misma protección y derechos que los nacionales de un Estado Miembro.

- Independencia del derecho

Independientemente del origen del derecho de propiedad industrial, respecto de la marca o de la patente cuyo registro o depósito se procura, los países miembros pueden aplicar sólo su legislación interna al determinar las condiciones de presentación y de registro.

- El uso del derecho

En materia de patentes se protege al titular de la patente, en el país donde la patente es concedida, en el caso de licencias obligatorias, se otorgarán por no explotar la patente.

Son partes de la Convención, Guatemala, El Salvador, Honduras, Nicaragua, Costa Rica (Fuente: Secretaría de Integración Económica Centro Americana); Belice y Panamá (Fuente: Organización Mundial de la Propiedad Intelectual, marzo 2004).

\subsection{Acuerdo sobre los Aspectos de los Derechos de Propiedad Intelectual relacionados con el Comercio (ADPIC).}

Se sostiene que cumpliendo con las disposiciones de los ADPIC, se evitará que la carencia y deficiencia en la protección de los derechos intelectuales generen distorsiones comerciales, como la piratería.

$\mathrm{Al}$ tratarse de un arreglo comercial, los ADPIC refleja un acentuado pragmatismo. De ahí, que en su texto se encuentra disposiciones alusivas a los derechos intelectuales como instrumentos de fomento o impulso a la creación y el comercio y hasta las previsiones de cooperación técnica están dirigidas hacia la protección y observancia de estos derechos.

En la primera parte el tratado reconoce los efectos legales de todas las disposiciones de los tratados multilaterales en el campo del comercio.

En lo relacionado con la propiedad industrial reconoce las disposiciones del Convenio de París, reconociendo en éste el Convenio más importante sobre la propiedad industrial, determinando en el artículo 2 que: "En lo que respecta a las 
partes II, III, y IV del presente Acuerdo, los miembros cumplirán los artículos 1 a 12 y el artículo 19 del Convenio de París".

Reconoce además de la regla de trato nacional, el principio de la nación más favorecida NMF, es decir todo privilegio, ventaja o inmunidad que conceda un Miembro a los nacionales de cualquier otro país, e otorgará inmediatamente y sin condiciones a los nacionales de todos los demás Miembros.

Determina que la expresión propiedad intelectual abarca todas las categorías de propiedad intelectual: Derecho de Autor y Derechos Conexos, Marcas de Fábrica o de Comercio, Indicaciones Geográficas, Dibujos y Modelos Industriales, Patentes, Esquemas de Trazados de Circuitos Integrados, Protección de la Información no Divulgada.

Los ADPIC establecen una protección mínima, es decir los Estados pueden otorgar en su legislación nacional una protección más amplia.

Es importante hacer referencia a los objetivos: "La protección y la observancia de los derechos de propiedad intelectual deberán contribuir a la promoción de la innovación tecnológica y a la transferencia y difusión de la tecnología, en beneficio recíproco de los productores y de los usuarios de conocimientos tecnológicos y de modo que favorezcan el bienestar social y económico y el equilibrio de derechos y obligaciones".

Establece como principios, que los Miembros al formular o modificar sus leyes y reglamentos, podrán adoptar las medias necesarias para proteger la salud pública y la nutrición de la población, o para promover el interés público en sectores de importancia vital para su desarrolló socioeconómico y tecnológico, siempre que esas disposiciones sean compatibles con lo previsto en el Acuerdo.

A efectos del presente trabajo, uno de los artículos más importante es el 27, el cual expresa:

a. Sin perjuicio de lo dispuesto en los párrafos 2 y 3, las patentes podrán obtenerse por todas las invenciones, sean de productos o de procedimientos, en todos los campos de la tecnología, siempre que sean nuevas, entrañen una actividad inventiva y sean susceptible de aplicación industrial. Sin perjuicio de lo dispuesto en el párrafo 4 del artículo 65, en el párrafo 8 del artículo 70 y en párrafo 3 del presente artículo, las patentes se podrán obtener y los derechos de patentes se podrán gozar sin discriminación por el lugar de la invención, el campo de la tecnología o el hecho de que los productos sean importados o producidos en el país.

b. Los Miembros podrán excluir de patentabilidad las invenciones cuya explotación comercial en su territorio deba impedirse necesariamente para proteger 
el orden público o la moralidad, inclusive para proteger la salud o la vida de las personas o de los animales o para preservar los vegetales, o para evitar daños graves al medio ambiente, siempre que esa exclusión no se haga meramente porque la explotación esté prohibida por su legislación.

c. Los miembros podrán excluir asimismo de la patentabilidad:

c.1 Los métodos de diagnóstico, terapéuticos y quirúrgicos para el tratamiento de personas y animales.

c.2 Las plantas y los animales excepto los microorganismos, y los procedimientos esencialmente biológicos para la producción de plantas o animales, que no sean procedimientos no biológicos o microbiológicos. Sin embargo, los Miembros otorgarán protección a todas las obtenciones vegetales mediante patentes, mediante un sistema eficaz sui generis o mediante una combinación de aquellas y éste. Las disposiciones del presente apartado serán objeto de examen cuatro años después de la entrada en vigor del acuerdo sobre la OMC".

La disposición general prevista en el artículo 27.1 obliga al patentamiento de productos y procedimientos en todos los campos tecnológicos, pero al señalar las exclusiones, se refiere a plantas en general, artículo 27.3, y no a variedades vegetales, es decir independiente de su clasificación taxonómica, los países Miembros podrían excluir de patentamiento todas las plantas, pero al no mencionar genes y células vegetales, ni productos derivados, éstos podrán ser objeto de patentes de productos, siempre y cuando cumplan con las condiciones objetivas de patentabilidad.

El artículo 27.3.b plantea como excepción para excluir de la patentabilidad a las plantas, al obligar por esa vía a otorgar protección a todas las obtenciones vegetales mediante patentes, mediante un sistema sui generis o mediante una combinación de aquellas y éste. Cuando se refiere a la denominación sui generis está referido al sistema de obtentores vegetales de UPOV.

Siempre relacionado al artículo 27.b.3 párrafo uno, la mención expresa de los procedimientos esencialmente biológicos significa que quedarán excluidos de la patentabilidad los procedimientos puramente biológicos, es decir, aquellos en que no existe intervención humana. La excepción también comprende a los procedimientos que esencialmente tengan tal carácter, aunque, accesoriamente empleen dispositivos técnicos, en el entendido que los dispositivos técnicos accesorios son patentables., No queda excluido de la patentabilidad todo procedimiento esencialmente biológico, sino, únicamente aquellos que tengan por objeto la obtención 
de vegetales o animales. Por tanto, cabría pensar en procedimientos esencialmente biológicos con otro objetivo, tales como combatir ciertas enfermedades de vegetales o plantas, etc. Se afirma que, todo procedimiento esencialmente biológico es un procedimiento mixto de elementos biológicos y técnicos y la excepción a la patentabilidad surge cuando predominan los elementos biológicos.

Cobra gran importancia en la actividad agropecuaria la protección a los modelos de utilidad, esa "petite" invención, que puede ser utilizado por las Universidades y Centros Tecnológicos y por la industria en general, de gran utilidad en la elaboración y/o fabricación de implementos agroindustriales.

Por ultimo, destaco la protección de la información no divulgada, contra la competencia desleal, esto guarda estrecha relación con los medicamentos veterinarios y los plaguicidas orgánicos o no, es importante recordar que esa información se encuentra bajo el resguardo y por consiguiente responsabilidad de oficinas de Gobierno.

Entró en vigencia los ADPIC en Guatemala, El Salvador, Honduras, Nicaragua, Costa Rica, Belice y Panamá(Fuente: Secretaría de Integración Económica Centro Americana).

\subsection{Convenio Internacional para la Protección de las Obtenciones Vegetales Acta de 1978}

La protección prevista en la Unión Internacional para la Protección de las Obtenciones Vegetales es una forma de protección sui generis; el Convenio se creo en 1961, entró en vigencia en 1968, sufrió modificaciones en 1972 y 1978 y nuevamente en 1991, es esa fecha el Convenio se modificó sustancialmente.

El Convenio tiene por objeto reconocer y garantizar un derecho al obtentor de una variedad vegetal nueva. Determina que se puede reconocer el derecho del obtentor mediante la concesión de un título de protección particular o una patente; con la salvedad de que si un Estado reconoce ambas formas de protección, deberá aplicar solamente una de ellas a un mismo género o una especie botánica.

Incorpora el principio de trato nacional, del cual hemos hablado, y el de reciprocidad. El cual consiste en, que todo Estado de la Unión que aplique el Convenio a un género o especie determinado tendrá facultad de limitar. el beneficio de la protección a los nacionales del Estado de la Unión que aplique el Convenio a ese género o especie y a las personas naturales o jurídicas con domicilio o residencia en uno de derechos Estados. 
En cuanto a su ámbito de aplicación, el Convenio es aplicable a todos los géneros y especies botánicos.

En lo relacionado al alcance de la protección que otorga el derecho del obtentor, consiste en la necesidad de solicitar autorización al obtentor para:

- La producción con fines comerciales.

- La puesta en venta.

- La comercialización del material de reproducción o de multiplicación vegetativa.

No afecta el alcance de la protección el uso propio o excepción del agricultor.

Existen algunas limitaciones al derecho del obtentor que son:

- El de emplear la variedad como origen inicial de variación con vistas a la creación de otras variedades, ni para la comercialización de éstas.

- Limitar el derecho exclusivo concedido al obtentor por razones de interés público.

El derecho otorgado al obtentor tiene una duración no inferior a quince años a partir de la concesión del título de obtentor; para las vides, árboles frutales, ornamentales, forestales la duración no podrá ser inferior a dieciocho años a partir de dicha fecha.

Los requisitos a cumplir para disponer del título de obtentor son:

- Sea el origen, artificial o natural, de la variación inicial que ha dado lugar a la variedad, ésta debe poder distinguirse claramente por uno o varios caracteres importantes de cualquier otra variedad, cuya existencia sea notoriamente conocida.

- En la fecha de presentación de la solicitud de protección en un Estado de la Unión no deberá haberse ofrecido en venta desde hace más de un año. En otros Estados por un período superior a seis años para las vides, árboles forestales, frutales y ornamentales y para otras plantas un periodo anterior superior a cuatro años.

- La variedad debe ser homogénea considerando las particularidades que presente su reproducción asexuada o su multiplicación vegetativa.

- Debe ser estable en sus caracteres esenciales.

- Debe debe recibir una denominación (identificación de la variedad).

Ratificaron el Acta de 1978, Nicaragua y Panamá (Fuente: UPOV).

Cabe mencionar que a raíz del proceso de negociación del Acuerdo de Libre Comercio entre Estados Unidos de América y Centroamérica, se plantea en el texto puesto a disposición del público por el Ministerio de Fomento Industria y 
Comercio de Nicaragua en el Capítulo Quince, Derechos de Propiedad Intelectual, artículo 15.1:5.:

"Salvo que se establezca lo contrario en este párrafo, cada Parte ratificará o accederá al Convenio Internacional para la Protección de las Obtenciones Vegetales (1991) (Convenio UPOV 1991). Antes del 1 de enero de 2006. .... No obstante lo anterior, cualquier parte que sea parte del Convenio Internacional para la Protección de las Obtenciones vegetales (1978) ratificará o accederá el Convenio UPOV 1991 antes del 1 de enero del 2010“.

Sostienen expertos que los cambios significativos que introdujo el Acta de 1991 consisten en:

- prolongación del periodo de protección.

- limitación al uso de la semilla guardada por el productor.

- derechos sobre el material cosechado y sus productos.

- permiso para el uso de múltiples tipos de protección.

- adopción del concepto de variedades esencialmente derivadas.

\subsection{Tratado internacional sobre los recursos fitogenéticos para la alimentacion y la Agricultura}

La Conferencia de la FAO en noviembre de 2001 aprobó el Tratado Internacional sobre los Recursos Fitogenéticos para la Alimentación y la Agricultura, por medio de Resolución 3/2001, el Tratado entra en vigor el 29 de junio de 2004. Siendo firmado por Guatemala y Costa Rica; Honduras y Nicaragua se adhirieron; El Salvador lo ratificó (Fuente: FAO).

El Tratado sustituye al Compromiso Internacional, un acuerdo no vinculante para la protección y uso de los recursos fitogenéticos para la alimentación y la agricultura, que existe desde 1983 en el marco de la FAO y cuyas disposiciones debieron ser revisadas luego de la aprobación del Convenio sobre la Diversidad Biológica. El Tratado regula algunas de las áreas de problemas controvertidos, así como aquellos que fueron excluidos del Convenio sobre la Diversidad Biológica, para no poner en riesgo su aprobación. Nos referimos, entonces, a los derechos del agricultor y el tratamiento de las colecciones ex situ de recursos fitogenéticos en centros de investigación nacional e internacional.

El Tratado reconoce los derechos del agricultor, es decir acceder a buenas semillas; tampoco debe limitarse los derechos a conservar, utilizar, intercambiar y vender semillas obtenidas en su finca. Estos derechos se plantean que servirán de contrapeso a los derechos de propiedad intelectual. 
Determina que las Partes Contratantes se comprometan a proporcionar y/o el acceso a las tecnologías para la conservación, caracterización, evaluación y utilización de los recursos fitogenéticos para la alimentación y la agricultura que estén comprendidos en el sistema multilateral. La transferencia de tecnología a los países en desarrolló debe ser fomentada, pero reconociendo y protegiendo eficazmente los derechos de propiedad intelectual.

Podrán obtenerse recursos del sistema multilateral con fines de utilización y conservación para la investigación, el mejoramiento y la capacitación. Cuando se obtiene un producto comercial utilizando estos recursos, el tratado prevé el pago de una parte equitativa de los beneficios monetarios resultantes, siempre que el producto no pueda ser utilizado sin restricción por otros para investigación y mejoramiento ulterior; en cambio si otros otros pueden utilizarlo, el pago será voluntario.

Las Partes Contratantes acuerdan un acceso facilitado a los recursos fitogenéticos dentro del sistema multilateral, dicho acceso debe ser concedido rápidamente y a costos mínimos, por medio de un acuerdo de transferencia de material.

Los receptores no reclamarán derechos de propiedad intelectual o de otra índole que limite el acceso facilitado a los recursos fitogenéticos para la alimentación y la agricultura, o sus partes o componentes genéticos, en la forma recibida del sistema multilateral.

El sistema multilateral incluye los recursos fitogenéticos que forman parte del anexo de Tratado, que están bajo la administración y control de las partes Contratantes y que son de dominio público.

Sostiene la Comisión de Recursos Genéticos para la Alimentación y la Agricultura que se benefician del Tratado:

- Los agricultores a través del derecho del agricultor.

- Los consumidores al obtener una mayor variedad de alimentos, y porque aumentará su seguridad alimentaria.

- Los científicos y fitomejoradores al acceder a nuevos recursos fitogenéticos para continuar ampliando sus investigaciones.

- Los centros internacionales de investigación agrícola, a cuyas colecciones el Tratado ofrece una base jurídica a largo plazo.

- Los sectores público y privado, a los que se asegura el acceso a una amplia gama de diversidad genética para contribuir a mejorar el desarrolló agrícola.

- El medio ambiente, porque el Tratado ayudará a conservar la diversidad genética. 
Hago referencia al Tratado Internacional sobre Recursos Fitogenéticos para la Alimentación y la Agricultura debido a la relación directa que guarda los derechos del agricultor con el Acta de UPOV de 1978 y la legislación nacional sobre protección de obtenciones vegetales.

Existe también, una relación estrecha entre el Tratado y la preservación de los derechos de propiedad intelectual.

Así mismo, la importante relación estratégica del Tratado con el trabajo de fitomejoramiento y los centros internacionales de investigación agrícola.

Por consiguiente, el acceso a nuevos materiales genéticos contribuirá al trabajo de fitomejoramiento para obtener mejores y adecuados materiales.

\subsection{Convenio sobre la diversidad biologica}

El Programa para el Medio Ambiente de las Naciones Unidas a partir de 1988 convocó a un Grupo de Trabajo Ad- Hoc para explorar la necesidad de un Convenio Internacional sobre la Diversidad Biológica, el largo trabajo desarrolló culminó en 1992 con la Conferencia de Narobi, en donde se adoptó el Texto Acordado del Convenio de Diversidad Biológica, el mismo entró en vigencia el 29 de diciembre de 1993. Los países de Guatemala, Honduras, El Salvador, Nicaragua, Costa Rica, Belice y Panamá lo ratificaron (Fuente: Convenio sobre Diversidad Biológica).

Surge una pregunta interesante, si analizamos aspectos relacionados a la propiedad intelectual y su relación con la actividad agropecuaria, que relación guarda lo anterior con el Convenio sobre Diversidad Biológica ?. Tratemos de aclarar esa inquietud.

Se plantea como objetivos del Convenio la conservación de la diversidad biológica, la utilización sostenible de sus componentes y la participación justa y equitativa en los beneficios que se deriven de la utilización de los recursos genéticos, mediante un acceso adecuado a esos recursos y una transferencia apropiada de las tecnologías.

Determina, entre otras cosas, que cada Parte contratante se compromete a asegurar y/o facilitar a otras Partes Contratantes el acceso a tecnologías pertinentes para la conservación y utilización sostenible de la diversidad biológica o que utilicen recursos genéticos y no causen daños significativos al medio ambiente, así como la transferencia de esas . Precisa, además, que en el caso de tecnología sujeta a patentes y otros derechos de propiedad intelectual, el acceso a esa tec- 
nología y su transferencia se asegurarán en condiciones que tengan en cuenta la protección adecuada y eficaz de los derechos de propiedad intelectual.

Determina que cada Parte Contratante tomará medias legislativas, administrativas o de política. Con el objeto de que se asegure a las Partes Contratantes, en particular las que son países en desarrolló, que aporten recursos genéticos, el acceso a la tecnología que utilice ese material y la transferencia, en condiciones acordadas, incluida la tecnología protegida por patentes y otros derechos de propiedad intelectual.

Para finalizar, se plantea que las Partes Contratantes, reconociendo que las patentes y otros derechos de propiedad intelectual pueden influir en la aplicación del presente Convenio, cooperarán a este respecto de conformidad con la legislación nacional y el derecho internacional para velar por que esos derechos apoyen y no se opongan a los objetivos del presente Convenio.

\subsection{Tratado de Budapest sobre reconocimiento internacional del depósito de microorganismos a los fines del procedimiento en materia de patentes}

El mismo fue suscrito en 1977, y modificado en 1980. Ningún país de Centro américa, Belice y Panamá lo han suscrito (Fuente:OMPI).

Realizo una breve referencia, ya que de ser ratificado el Acuerdo de Libre Comercio entre Estados Unidos de América y Centroamérica, existe la obligación de ratificarlo o accederle antes del 1 de enero de 2006.

Se constituyen en Unión los Estados parte del Tratado, para el reconocimiento internacional del depósito de microorganismos a los fines del procedimiento en materia de patentes.

Define como depósito de un microorganismo: "La transmisión de un microorganismo a una autoridad internacional de depósito, que lo recibe y acepta, o la conservación de tal microorganismo por la autoridad internacional de depósito, o la transmisión y conservación simultáneamente“.

Los Estados contratantes que permitan o exijan el depósito de microorganismos, reconocerán el depósito de un microorganismo efectuado ante una autoridad internacional. El reconocimiento comprende el hecho y además la fecha del depósito, también el reconocimiento de que lo que se entrega en calidad de muestra, corresponde a una muestra del microorganismo depositado.

Para disponer del derecho al estatuto de autoridad internacional de depósito, una institución de depósito deberá estar domiciliada en el territorio de 
un Estado contratante. Una institución de depósito adquiere el estatuto de autoridad internacional de depósito en virtud de una declaración escrita dirigida al Director General por el Estado contratante, acompañada de otras informaciones.

En nuestro continente, existen las siguientes autoridades internacionales de depósito:

Agricultural Research Service Culture Collection (NRRL),American Type Culture Collection (ATCC) en Estados Unidos de América y National Microbiology Laboratory Health Canada ( NMLCH) en Canadá (Fuente: OMPI).

\section{Algunos aspectos sobre legislacion nacional}

En el presente capítulo, analizo aquellos aspectos fundamentales de las regulaciones nacionales en propiedad intelectual relacionados a la actividad agropecuaria, tomando como referencia las disposiciones de los principales instrumentos internacionales en la materia.

\subsection{Inventario de leyes}

El primer paso, consiste en conocer cual es el marco regulatorio en propiedad industrial y los derechos sui generis o nuevas tecnologías.

\section{Guatemala}

- Ley de Propiedad Industrial, Decreto No.57-2000.

- Reglamento de la Ley de Propiedad Industrial, Acuerdo Gubernativo No.892002.

\section{El Salvador}

- Ley de Fomento y Protección de la Propiedad Intelectual, Decreto No. 604.

- Reglamento de la Ley de Fomento y Protección de la Propiedad Intelectual.

- Ley de Marcas y Otros Signos Distintivos, Decreto No.868 Asamblea Legislativa.

\section{Honduras}

- Ley de Propiedad Industrial, Decreto No. 12-99-E.

\section{Nicaragua}

- Acuerdo entre el Gobierno de la República de Nicaragua y el de los Estados Unidos de América, a cerca de la Protección de los Derechos de Propiedad Intelectual.

- Ley de Protección para las Obtenciones Vegetales, Ley No. 318.

- Reglamento para la Ley de Protección para las Obtenciones Vegetales. 
- Ley de Patentes de Invención, Modelo de Utilidad y Diseños Industriales, ley No. 354.

- Reglamento de la Ley de Patentes de Invención, Modelo de Utilidad y Diseños Industriales.

- Ley de Marcas y Otros Signos Distintivos, Ley No. 380.

- Ley General del Medio Ambiente

\section{Costa Rica}

- Ley de Patentes, de Invención, Dibujo y Modelos Industriales y Modelos de Utilidad, Decreto No. 6867.

- Reglamento a la Ley de Patentes, de Invención, Dibujo y Modelos Industriales y Modelos de Utilidad.

- Ley de Marcas y Otros Signos Distintivos, Decreto No. 7978.

- Reglamento a la Ley de Marcas y Otros Signos Distintivos.

- Ley de Información no Divulgada, Decreto No. 7975.

- Ley de Procedimientos de Observancia de los Derechos de Propiedad Intelectual, Ley No. 8039.

- Ley para Identificar el Banano de Costa Rica en los Mercados Internacionales, Ley No. 8063.

- Ley de Biodiversidad, Decreto No. 7788.

\section{Panamá}

- Disposiciones sobre Propiedad Intelectual, Ley No. 35.

- Reglamento de la Ley sobre Propiedad Intelectual.

\section{Belice}

- Ley de Dibujos y Modelos Industriales, 2000.

- Ley de Patentes 2000.

- Ley de Protección de las nuevas Obtenciones Vegetales, 2000.

- Ley de Marcas de Fábrica o de Comercio, 2000.

\subsection{Obtenciones vegetales}

En tres legislaciones se observan aspectos bastantes coincidentes sobre los temas siguientes:

- Determina los criterios para otorgar el título de obtentor: novedad, distinta, homogénea, estable y tener una denominación.

- Establece cual es el alcance del derecho del obtentor: Requiere de la autorización del obtentor la producción o reproducción, la oferta en venta, el repetido uso de la nueva variedad para la producción comercial de otra varie- 
dad, exportación, importación, preparación a los fines de reproducción o de multiplicación.

- Las normativas de Belice y Nicaragua incorporan la definición de variedad esencialmente derivada (Acta de 1991).

- Sobre las excepciones del agricultor: Cuando constituya fuente o insumos de investigación para el mejoramiento genético de otras variedades vegetales, actos realizados en un marco privado con fines no comerciales, preserva el derecho del agricultor (uso propio).

- Duración de la protección: Panamá y Belice aplican lo previsto en el Acta de 1991, 20 años , pero para árboles y vides 25 años; Nicaragua señala un plazo único que es de 20 años.

Guatemala, por medio de la Ley de Propiedad Industrial dispone de patente para variedades vegetales; determina como requisitos específicos de patentabilidad que la variedad vegetal sea nueva, distinta, homogénea y estable.

\subsection{Patente}

A continuación, señalo aspectos comunes y fundamentales sobre la legislación de patente.

Definen como invento: “ Una creación aplicable en la práctica para la solución de un problema técnico. Podrá ser un producto o un procedimiento, o estar relacionado con ellos".

En cuanto a patente señalan: " Es el derecho exclusivo que otorga el Estado para la protección de un invento. Los efectos, obligaciones y limitaciones inherentes a la patente, están determinados por la presente Ley".

Establecen que no constituyen patente, entre otros:

- Los simples descubrimientos.

- Las materias o las energías en la forma en que se encuentran en la naturaleza.

- Los procedimientos biológicos tal como ocurren en la naturaleza y que no supongan intervención humana, salvo los procedimientos microbiológicos.

- Las teorías científicas y los métodos matemáticos.

- Las creaciones puramente estéticas, las obras literarias y artísticas.

- Los programas de computación aisladamente considerados.

- Los planes, principios, reglas o métodos económicos, de publicidad o de negocios, y los referidos a actividades puramente mentales o intelectuales, o materia de juegos. 
Se considera como materia excluida de patente:

- Los métodos de diagnóstico, terapéuticos y quirúrgicos para el tratamiento de personas o animales.

- Una invención cuya explotación sería contraria al orden público o la moral, entendiéndose que la explotación no se considerará contraria al orden público o a la moral solamente por razón de estar prohibida, limitada o condicionada por alguna disposición legal o administrativa.

- Una invención cuya explotación comercial fuese necesario impedir para preservar la salud o la vida de las personas, animales o plantas o el medio ambiente.

Consideran como requisitos de patentabilidad:

- Que la invención tenga novedad, nivel inventivo, y sea susceptible de aplicación industrial.

- Duración de la protección:

- La protección dura 20 años improrrogables.

- Conviene mencionar que la legislación de Guatemala y Nicaragua en materia de patente aborda dos aspectos novedosos:

- Descripción de material biológico y validez del depósito y además alcance de patentes para biotecnología.

\subsection{Modelos de utilidad}

En la legislación analizada encontramos elementos comunes, veamos algunos de estos.

Se define el modelo de utilidad como : "Toda mejora o innovación en la forma, configuración o disposición de elementos de algún objeto, artefacto, herramienta, instrumento, mecanismo o de una parte del mismo, que le proporcione algún efecto técnico en su fabricación o uso, o que le proporcione alguna utilidad, ventaja, o efecto técnico, que antes no tenía".

\section{No podrán ser objeto de una patente de modelo de utilidad:}

- Los procedimientos.

- Las sustancias o composiciones.

- La materia excluida de patentabilidad.

- Cuando no aporta ninguna característica utilitaria discernible respecto a invenciones o a modelos de utilidad anteriores.

Un modelo de utilidad será patentable cuando sea susceptible de aplicación industrial y tenga novedad..

Entre otros, se consideran modelos de utilidad los utensilios, objetos, aparatos, instrumentos, herramientas y dispositivos, así como las partes de los mismos, 
que como resultado de una modificación en su disposición, configuración, estructura o forma presenten una función diferente respecto de las partes que lo integran o ventajas en cuanto su utilidad.

La vigencia de la patente de utilidad será por un plazo de 10 años improrrogables a partir de la fecha de presentación.

\subsection{Diseños industriales}

Dentro del marco regulatorio objeto del presente análisis encuentro varios aspectos que son comunes, de los cuales destacó los siguientes.

Se conceptualiza el diseño industrial como aquel que:

"Comprende tanto los dibujos como los modelos industriales, los primeros deben entenderse como toda la combinación de figuras, líneas o colores, que incorporen a un producto industrial o artesanal, con fines de ornamentación y que le den una apariencia particular y propia; los segundos como toda forma tridimensional, que sirva de tipo o patrón para la fabricación de un producto industrial, que le dé un aspecto especial y que no tenga fines funcionales técnicos”.

El diseño industrial será protegido si es Nuevo. Se considera la novedad, cuando el diseño industrial no ha sido divulgado públicamente.

El diseño industrial goza de protección sin registro durante el plazo de 3 años; el registro de un diseño industrial será de 10 años, el plazo podrá ser renovado por una sola vez por 5 años.

La protección de un diseño industrial no comprende:

Aquellos elementos o características del mismo determinados enteramente por la realización de una función técnica y que no incorporen algún aporte novedoso del diseñador; y aquellos elementos o caraccterísticas cuya reproducción fuese necesaria para permitir que el producto que incorpora el diseño sea montado mecánicamente o conectado con otro producto del cual constituya una parte o pieza integrante. Esta limitación no se aplicará tratándose de productos en los cuales el modelo radica en una forma destinada permitir el montaje o la conexión dentro de un sistema modular.

\subsection{Marcas y otros signos distintivos}

En cuanto a las marcas y otros signos distintivos, algunos aspectos comunes son: Se define que marca es: "Cualquier signo denominativo, figurativo, tridimensional o mixto perceptible visualmente, que sea apto para distinguir los productos o servicios de una persona individual o jurídica de los de otra”. 
En cuanto a signo distintivo: "Cualquier signo que constituya una marca, un nombre comercial, un emblema, una expresión o señal de propaganda o una denominación de origen".

Dentro de los signos que pueden constituir marca puedo mencionar:

Palabras o conjunto de palabras, letras, cifras, monogramas, figuras, retratos, etiquetas escudos, estampados, viñetas, orlas, líneas y franjas, y combinaciones y disposiciones de colores, así como cualquier combinación de estos signos. Pueden asimismo consistir en la forma, presentación o acondicionamiento de los productos o de sus envases o envolturas, o de los medios o locales de expendio de los productos o servicios correspondientes.

Son caracteres esenciales de las marcas:

La marca debe individualizar la fuente de procedencia, por consiguiente debe tener:

- Originalidad

La originalidad estriba en que no tenga relación con la naturaleza de la mercancía a la que esta destinada, es decir no puede apropiarse del nombre genérico o común de un bien o de sus cualidades.

- Novedad

La marca identifica un producto o un servicio entre los productos o servicios de la misma especie o clase de los productos de la competencia, evitando la confusión con otras marcas existentes en el mercado e inscritas.

Entonces, el derecho protege al titular contra todo acto de uso por terceros que incida en la distintividad de su marca, que afecte a la función identificadora que le corresponde cumplir.

Tengamos presente que el empresario impone la marca a todos los ejemplares. $\mathrm{Y}$ al ser único el empresario, significa que todos los productos o servicios así marcados, proceden de el, que es por el que son idénticos, son iguales.

Algunos de los derechos exclusivos conferidos por el registro de una marca son:

- Aplicar o colocar la marca o un signo distintivo idéntico o semejante sobre productos para los cuales se ha registrado la marca, o sobre productos incluidos a los servicios para los cuales se ha registrado la misma, o sobre envases, envolturas, embalajes o acondicionamientos de tales productos.

- Suprimir o modificar la marca con fines comerciales después de que se hubiese aplicado o colocado sobre los productos referidos en el inciso anterior.

- Fabricar etiquetas, envases, envolturas, embalajes u otros materiales que reproduzcan o contengan la marca, así como comercializar o detentar tales materiales. 
- Rellenar o reutilizar con fines comerciales envases, envolturas o embalajes que llevan la marca.

- Usar en el comercio un signo idéntico o similar a la marca respecto de cualesquiera productos o servicios cuando tal uso pudiese causar confusión o un riesgo de asociación con el titular del registro, quedando entendido que tratándose del uso de un signo idéntico para productos o servicios idénticos se presumirá que existe probabilidad de confusión.

- Usar en el comercio un signo idéntico o similar a la marca respecto de cualesquiera productos o servicios cuando tal uso pudiese causar al titular del registro un daño económico o comercial injusto por razón de una dilución de la fuerza distintiva o del valor comercial o publicitario de la marca, o de un aprovechamiento injusto del prestigio de la marca o de su titular.

- Usar públicamente un signo idéntico o similar a la marca, aun para fines no comerciales, cuando ello pudiese causar una dilución de la fuerza distintiva o del valor comercial o publicitario de la marca, o un aprovechamiento injusto de su prestigio.

El registro de una marca vencerá a los 10 años, contados desde la fecha de su concesión. Podrá ser renovada indefinidamente por períodos sucesivos de 10 años.

\subsection{Indicaciones geográficas}

Dentro de las marcas, nos encontramos con las indicaciones geográficas, se plantea que la indicación geográfica es: " Nombre, expresión, imagen o signo que designa o evoca a un país, una región, una localidad o un lugar determinado.

Una indicación geográfica es un signo utilizado para productos que tienen un origen geográfico concreto y poseen cualidades o una reputación derivadas específicamente de su lugar de origen. Una indicación geográfica consiste en el nombre del lugar de origen de los productos. Un ejemplo típico son los productos agrícolas que poseen cualidades derivadas de su lugar de producción, y están sometidas a factores locales específicos como el clima y terreno.

Una indicación geográfica hace referencia al lugar o región de producción que determina las cualidades específicas del producto originario de dicho lugar o región. Es importante considerar que las cualidades y la reputación del producto sean atribuibles a dicho lugar. Existiendo, por tanto, un vínculo concreto entre los productos y su lugar de producción original.

Una indicación geográfica no podrá usarse en el comercio en relación con un producto o un servicio cuando fuese falsa o engañosa con respecto al origen del producto o servicio, o cuando su uso pudiera inducir al público a confusión con respecto al origen, procedencia, calidad o cualquier otra característica. 
No podrá usarse en la publicidad, ni en la documentación comercial relativa a la venta, exposición u oferta de productos o servicios, una indicación susceptible de causar error o confusión sobre la procedencia geográfica de los productos o servicios. Tampoco se permitirá la utilización de marcas que contengan expresiones como: clase, tipo, estilo, imitación u otras análogas.

Dentro de las indicaciones geográficas encontramos las denominaciones de origen.

Se define como: Una indicación geográfica que identifica a un producto originario de un país, una región, una localidad o un lugar determinado cuya calidad, reputación u otra característica sea atribuible esencialmente a su origen geográfico, incluidos los factores humanos y naturales; también se considerará como denominación de origen la constituida por la denominación de un producto que, sin ser un nombre geográfico, denota una procedencia geográfica cuando se aplica a ese producto, cuya calidad, reputación u otra característica es atribuible esencialmente a su origen geográfico..

La denominación de origen es un tipo especial de indicación geográfica, que se aplica a productos que poseen una calidad específica derivada exclusiva o esencialmente del medio geográfico en el que se elaboran.

La solicitud de registro se presenta por cualquier entidad formalmente constituida que represente a dos o más productores, fabricantes o artesanos cuyos establecimientos de producción, elaboración o fabricación se encuentran en la región o en la localidad a la cual corresponde la denominación de origen; o a solicitud de una autoridad nacional competente.

Solamente los productores, fabricantes o artesanos que desempeñen su actividad dentro de la zona geográfica delimitada indicada en el registro podrán usar comercialmente la denominación de origen registrada para los productos respectivos. Solamente esos productores o fabricantes o artesanos podrán emplear la expresión: DENOMINACION DE ORIGEN.

\subsection{Informacion no divulgada}

No se dispone de regulación específica en lo relacionado a la divulgación de datos o información no divulgada en Centroamérica, la excepción es Costa Rica por medio de la Ley de Información no Divulgada.

\section{Dicha normativa en sus partes conducentes establece:}

"Protección de datos suministrados para aprobar la comercialización de productos farmacéuticos o agroquímicos. Si, como condición para aprobar la comercialización de productos farmacéuticos y agroquímicos que utilicen nuevas 
entidades químicas, se exige presentar datos de prueba u otros no divulgados cuya elaboración suponga un esfuerzo considerable, los datos referidos se protegerán contra todo uso comercial desleal y toda divulgación, salvo cuando el uso de tales datos se requiera para proteger al público o cuando se adopten medidas para garantizar la protección contra todo uso comercial desleal.

No obstante lo dispuesto en el primer párrafo del presente artículo, las autoridades competentes podrán utilizar datos de prueba sin divulgar la información protegida, cuando se trate de estudios contemplados en las reglamentaciones sobre registros de medicamentos o agroquímicos para prevenir prácticas que puedan inducir a error al consumidor o para proteger la vida, la salud o la seguridad humanas, o bien, la vida o salud animal o vegetal, o el medio ambiente a fin de prevenir el abuso de los derechos de propiedad intelectual o el recurso de prácticas que limiten el comercio injustificadamente".

A pesar de ese esfuerzo regulatorio, quedan vacíos, para precisar de mejor manera como resolver esos vacíos veamos lo que establece sobre el mismo tema el proyecto de texto de Acuerdo de Libre Comercio entre Estados Unidos de América y Centroamérica:

"Si una Parte exige, como condición para aprobar la comercialización de nuevos productos farmacéuticos y químicos agrícolas, la presentación de datos no divulgados sobre la seguridad y eficacia, esa Parte no permitirá que terceros, que no cuenten con el consentimiento de la persona que proporciona dicha información, comercialicen un producto sobre la base de tal información o la aprobación otorgada a la persona que presentó la información, por un período de al menos 5 años para productos farmacéuticos y 10 años para productos químicos agrícolas desde la fecha de aprobación“.

\subsection{Transferencia de tecnología}

En las legislaciones analizadas encuentro diferentes modalidades de explotación de los derechos de propiedad intelectual, tales como la cesión o transferencia de patente, licencia para explotación de la invención; enajenación del derecho sobre una marca registrada o en trámite, licencia de uso de una marca; transmisión del derecho del obtentor. Pero además puede transferirse tecnologías por medio del contrato de franquicia; contrato de Know How, etc.

La cesión o transferencia implica que el titular de los derechos de una patente, una marca, un derecho de obtentor, podrá ceder o transferir total o parcialmente esos derechos a un tercero. 
En cambio, por medio de una licencia, el titular del derecho respectivo podrá otorgar la autorización únicamente para el uso o explotación de la patente, marca o derecho del obtentor, a un tercero.

Por medio del contrato de know how el licenciante autoriza al licenciatario a utilizar una técnica desarrollada y mantenida en secreto por el licenciante.

Por medio del contrato de franquicia, el franquiciante, pone a disposición del franquiciado el control de productos o servicios, que deben ser adaptados, y utilizados por el franquiciado.

Por consiguiente se puede adquirir nuevas tecnologías, o en caso contrario, aprovechar la creación intelectual de nuestros investigadores, fitomejoradores, centros nacionales de investigación agropecuaria, universidades, fabricantes de equipos y maquinaria agropecuaria, etc. para ponerla al alcance de terceros (productores); es decir, se trata de aprovechar al máximo ese valor agregado producto de años de investigación.

Por cualquiera de las dos vías, todo el sistema productivo de un país puede disponer de nuevas herramientas para alcanzar mejores rendimientos productivos y salir de la pobreza.

Pero que sucede en la actualidad, todavía el sistema no funciona correctamente en todos sus engranajes, se dispone de leyes en materia de propiedad intelectual, pero no se combate los actos de piratería, ni actos desleales de comercio; no se dispone de políticas de Gobierno dirigidas a la promoción de los derechos de propiedad intelectual; en las universidades (escuelas de derecho, ingeniería, diseño) y centros de investigación no se promueve de forma sistemática el conocimiento de la propiedad intelectual, ni tampoco como adquirir y sacar ventajas a esos derechos.

\subsection{Otros aspectos a destacar}

Costa Rica dispone de la Ley No. 8063, Ley para Identificar el Banano de Costa Rica en los Mercados Internacionales.

Corresponde a una Ley corta, de 5 artículos, determina que las personas naturales o jurídicas que exportan banano producido en su país están obligados a señalar el origen costarricense del mismo. La marca dirá la frase: “BANANO DE COSTA RICA".

En Costa Rica por medio de la Ley de Biodiversidad, Ley No.7788, se dedica una sección denominada Protección de los Derechos de Propiedad Intelectual e Industrial. 
Por medio de la cual, el Estado reconoce la existencia y validez de las formas de conocimiento e innovación y la necesidad de protegerlas. Esa protección $\mathrm{s}$ otorga por medio de patente, secretos comerciales, derechos del fitomejorador, derechos intelectuales comunitarios sui generis, derecho de autor, derechos de los agricultores. Obviamente se enumeran determinadas categorías de derechos comunitarios que, al ser de dominio público, no son compatibles con algunos derechos de propiedad intelectual tal es el caso de patentes, derecho de autor, secretos comerciales y otros.

Establecen excepciones para no otorgar derechos de propiedad intelectual a las plantas y animales, los procedimientos esencialmente biológicos, etc. Aspectos que las diferentes regulaciones nacionales en materia de patente señalan que no constituyen patente o que se considera como materia excluida de patente.

En Nicaragua, por medio de la Ley General del Medio Ambiente y los Recursos Naturales, Ley No. 217, señala que se registran y patentan a favor del Estado y del pueblo nicaraguense, para uso exclusivo o preferente, los germoplasmas y cada una de las especies nativas del territorio nacional.

Como se observará hay un craso error de los legisladores y de los promotores de la Ley, ya que como hemos conocido, los recursos naturales tal y como se encuentran en la naturaleza no constituyen patente, y además no cumplen con los requisitos de patentabilidad.

\section{Recomendaciones}

1- Debe disponerse de políticas de Estado dirigidas a promover el conocimiento y aplicación de la legislación en propiedad intelectual.

2- Es de necesidad que los centros de investigación agropecuarios, universidades, fitomejoradores, fabricas de equipos e implementos agropecuarios, y productores conozcan la legislación sobre propiedad intelectual y de manera especial las ventajas que pueden obtenerse al incorporar valor agregado al resultado de la creación intelectual.

3- Debe ser un esfuerzo del Estado en primer lugar, de las instituciones públicas o privadas, nacionales e internacionales, que impulsan o promueven el acceso a las nuevas tecnologías en materia agropecuaria, difundan los principales aspectos de la legislación en propiedad intelectual y cual es la relación que guarda cada una de las categorías de propiedad intelectualcon las diferentes actividades agrícolas y ganaderas: académicas, investigativas, productivas, industriales, fabriles y comerciales. 
4- El disponer de un marco regulatorio amplio y bastante completo en propiedad intelectual facilita la posibilidad de acceder a nuevas tecnologías y asumir con responsabilidad las obligaciones que se derivan.

5- Los centros de investigación agropecuaria que trabajan directamente con los Centros Internacionales de Investigación Agrícola están obligados a conocer las obligaciones para los Estados que ratificaron o están en proceso de ratificación del Tratado Internacional sobre los Recursos Fitogenéticos para la Alimentación y la Agricultura.

6- Debe promoverse la difusión de las regulaciones establecidas en acuerdos bilaterales o regionales de libre comercio sobre el tema de propiedad intelectual, actualmente destaco el Acuerdo de Libre Comercio entre Centro América y República Dominicana, y el posible Acuerdo con los Estados Unidos de América.

7- Los países de El Salvador, Honduras y Costa Rica deben aprobar su legislación para la protección de las obtenciones vegetales, preservando como excepciones al derecho del obtentor: El derecho del agricultor y cuando constituya fuente o insumos de investigación para el mejoramiento genético de otras variedades vegetales.

8- Es importante asegurar que exista una relación directa y sistemática entre loscentros o consejos nacionales de tecnología con la actividad agropecuaria, de forma particular sobre dos aspectos: Las nuevas tecnologías, transferencia de tecnología y propiedad intelectual.

9- Conviene conformar una comisión interinstitucional y por representantes del sector privado agropecuario y universidades a fin de realizar una investigación dirigida a identificar aquellos productos que se pudieran proteger como indicaciones geográficas o denominación de origen, con el fin de incorporar valor agregado.

\section{BIBLIOGRAFÍA}

- ASTUdiLlO GÓMEZ Francisco; La Protección Legal de las Invenciones, Especial Referencia a la Biotecnología; Universidad de Los Andes; 1era edición, 1995.

- Deutsche Gesellschaft fur Technische Zusammenarbeit (GTZ); El Tratado Internacional sobre los Recursos Fitogenéticos para la Alimentación y la Agricultura; Proyecto Sectorial "People and Biodiversity in Rural Areas"; Alemania.

- CASCARDO Renata, GIANI Carmen, PIANA José; Variedades Vegetales en Argentina; Latin Gráfica; Buenos Aires 1998. 
- GARON FIGULS Ricardo; La Propiedad Intelectual y su Relación con la Biotecnología y la Biodiversidad; La Propiedad Intelectual en la Integración Económica de Centroamericana; No. 1 Enero- Junio 1998; Guatemala.

- GOMEZ SEGADE José; Tecnología y Derecho; Marcial Pons; Madrid; 2001.

- GODOY VETANCOURT Clara M.; La Obtención de Variedades Vegetales y su Reglamentación en el Ambito Universitario; Mérida, Venezuela; 2000.

- GREENGRAS Barry;Simposio Conjunto UPOV-OMPI-OMC, Las Actas de 1978 y 1991 del Convenio de UPOV; Ginebra; 1999.

- MARTINeS PÉREZ Ana María; Competencia Desleal; Guatemala; 2000.

- ORUE CRUZ José René; Manual de Derecho Mercantil; HISPAMER;Managua; 2003.

- PARRA Ovidio; Sistema Internacional de Protección a la Propiedad Industrial; Guatemala; 2000.

- RAPELA Miguel Angel; Derechos de Propiedad Intelectual en Vegetales Superiores; Edit. Ciudad Argentina; Buenos Aires; 2000.

- Sistema de Información de Comercio Exterior; Derechos de Propiedad Intelectual.

- UPOV; Sus actividades y Cometido; Ginebra; 2003.

- YARZABAL Andrés; Biotecnología: Historia Perspectivas y Controversias; Biotecnología y Propiedad Intelectual; LIVROSCA; Caracas; 1999. 
